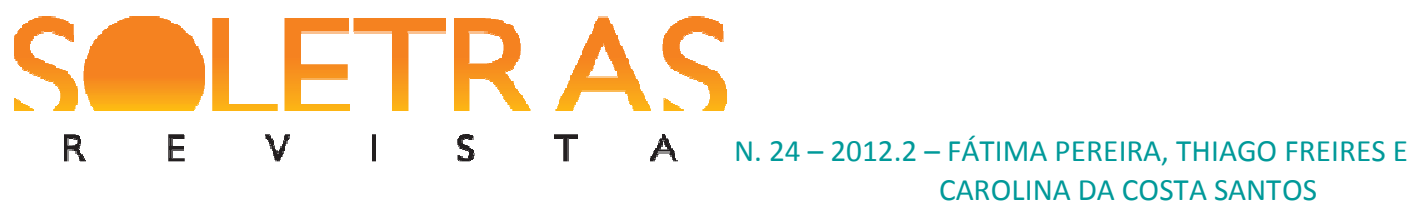

\title{
Efeitos da escolaridade no percurso de vida dos alunos: nas entrelinhas da narrativa $^{1}$
}

\author{
Fátima Pereira ${ }^{2}$ \\ Thiago Freires ${ }^{3}$ \\ Carolina da Costa Santos ${ }^{4}$
}

\begin{abstract}
Resumo: O presente artigo trata dos efeitos da escolaridade no percurso de vida de alunos de algumas escolas de Portugal que, em parceria com o Centro de Investigação e Intervenção Educativas - CIIE - da Faculdade de Psicologia e de Ciências da Educação da Universidade do Porto (FPCEUP), fazem parte do Observatório da Vida nas Escolas - OBVIE. O projeto de pesquisa objetiva compreender os impactos da instituição na qual o aluno tem sua experiência escolar em sua vida, sendo este artigo centrado nas entrelinhas que entrevistas de tipo biográfico permitiram-nos ler. As entrevistas, cujo guião foi pensado entre escolas e universidade, foram tecidas com alunos de idades e escolas diversas e apresentam-se como método de investigação que permite dar relevo à voz dos alunos. Esta pesquisa fundamenta-se a partir de um referencial teórico que privilegia a epistemologia da escuta discente. A relevância do artigo encontra-se, principalmente, em permitir que se entenda a importância da voz dos alunos dentro da polifonia escolar para se compreender os significados que os alunos a ela atribuem, em suas diferentes dimensões. Como resultados iniciais, apontamos que o "grito" dos alunos revela necessidade de se promover união e trabalho humanizado em todos os âmbitos escolares, indicando que, antes de estrutura, currículo e metodologias, a escola é constituída por pessoas.
\end{abstract}

Palavras-chave: Escola. Voz dos alunos. Experiências escolares.

\footnotetext{
${ }^{1}$ N.d.E. Ao receber o artigo da Professora da Universidade do Porto, optamos por manter a escrita original, com expressões e modos do português de Portugal.

${ }^{2}$ Fátima Pereira é Doutora em Ciências da Educação e Professora Auxiliar da Faculdade de Psicologia e de Ciências da Educação da Universidade do Porto (FPCEUP). Membro da Comissão Científica do Mestrado em Ciências da Educação e da Comissão de Ética e Vice-coordenadora do Serviço de Educação Contínua, da FPCEUP. Possui 6 livros publicados, 21 capítulos de livros, 30 artigos peer reviewed, 43 proceeding papers. Está envolvida em diversas redes de investigação internacionais na Europa e América Latina. E-mail: fpereira@ fpce.up.pt.

${ }^{\frac{3}{3}}$ Thiago Freires é Mestrando em Ciências da Educação pela Faculdade de Psicologia e de Ciências da Educação da Universidade do Porto e bolsista de investigação do programa Investigação Jovem na Universidade do Porto (IJUP). É licenciado em Letras (Português / Inglês) pela Universidade de São Paulo e especialista em Educação Infantil pelo Abbey College (Dublin, Irlanda). Atuou como professor de língua inglesa no Ensino Médio da rede privada de São Paulo e, atualmente, trabalha como roteirista de objetos didáticos digitais. E-mail: freiresle@gmail.com.

${ }^{4}$ Carolina da Costa Santos é licenciada em Pedagogia pela Universidade Federal do Estado do Rio de Janeiro UNIRIO - e em Letras (Português/Francês e respectivas literaturas) pela Universidade do Estado do Rio de Janeiro - UERJ. Atualmente cursa o mestrado em Ciências da Educação na Faculdade de Psicologia e Ciências da Educação da Universidade do Porto e é bolsista de investigação do programa Investigação Jovem na Universidade do Porto (IJUP). E-mail: mced11015@fpcep.up.pt.
} 


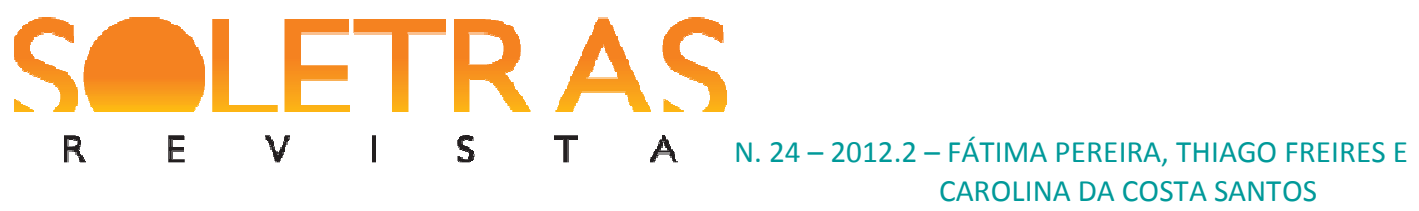

\section{Introdução}

Este artigo apresenta os resultados iniciais do projeto de investigação sobre os efeitos da escolaridade no percurso de vida de alunos de algumas escolas de Portugal, pesquisa realizada no âmbito do Observatório da Vida nas Escolas e do Projeto Pluridisciplinar de Iniciação à Investigação da Universidade do Porto. A discussão presente no trabalho incide na análise de trinta e quatro entrevistas realizadas com estudantes de diferentes escolas e revela os aspectos que mais se destacam, quer diretamente, através de respostas a perguntas pontuais, quer a partir das entrelinhas que os ditos e os não ditos permitem inferir. Assim, abordamos as questões da figura do professor e das relações entre pessoas na escola, passando pelas confluências entre a vida familiar e a vida escolar dos estudantes, sempre com base no quadro teórico da voz do aluno.

\section{O observatório da vida nas escolas}

O Observatório da Vida nas Escolas (OBVIE), integrado no Centro de Investigação e Intervenção Educativas (CIIE) da Faculdade de Psicologia e de Ciências da Educação da Universidade do Porto (FPCEUP), foi criado no início de 2008, e nasce do desejo de constituir uma rede de saberes por meio de contributos emergentes de projetos de investigação cujo objeto e / ou campo de estudo consideram a Escola em sua heterogeneidade, polifonia e possibilidades epistemológicas.

Nesse sentido, Mouraz e Pereira (2011) nos apontam que foram definidos como objetivos do OBVIE, a implementação de uma rede de recolha de informação fundamentada na utilização de metodologias de investigação e no estabelecimento de protocolos visando o acesso a dados atualizados sobre a vida nas escolas; a produção de conhecimento em diferentes domínios que tenham implicações nas formas de vida produzidas na escola; o conhecimento de especificidades dos processos educativos e relacionais experienciados em diferentes escolas; a criação de dispositivos de divulgação sistemática e atualizado do conhecimento produzido e; a realização de debates prospectivos com as comunidades educativa e científica sobre os resultados da atividade do observatório. 


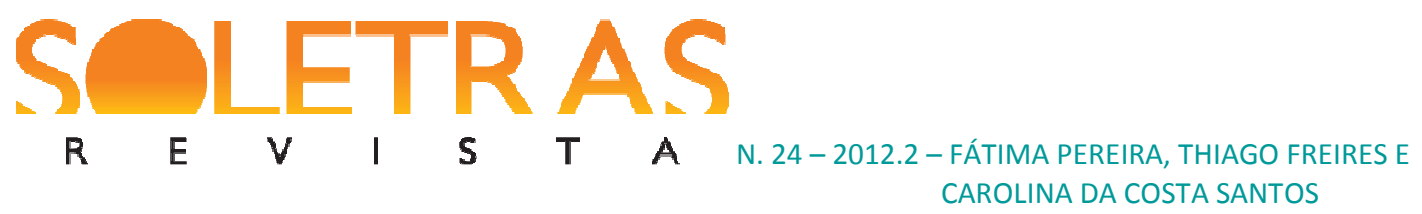

Situado num pressuposto de parceria, o projeto envolve dezesseis agrupamentos de escolas $^{5}$, situados especialmente no Norte de Portugal, não com o preceito de analisá-las, mas de contribuir de modo ativo para a produção de conhecimento sobre a vida no contexto escolar, por meio de procedimentos que promovem uma partilha e debate com os próprios sujeitos que vivenciam esse espaço e aqueles para quem esses saberes também são pertinentes. Assim, podemos dizer que os pressupostos da pesquisa envolvem uma apropriação dos resultados pelas escolas, em uma dimensão de liberdade e de respeito ao seu funcionamento.

A educação, como sabemos, está marcada pelo tempo e pelo lugar em que se produz e, por isso, concretiza-se em diversos contextos espaciais, sociais e históricos, não se isentando, assim, de refletir características dos mesmos (AMADO; BOAVIDA, 2006). Diante de transformações implicadas em novas configurações identitárias e em novas condições socioculturais e econômicas, geradas pelo contexto social atual, cabe perceber como o quotidiano da escola, das crianças e dos jovens, dos professores e das famílias é afetado de modo a instabilizar as práticas escolares, emergindo então uma necessidade de legitimar novos mandatos institucionais, em que as dimensões das relações educativas, dos saberes escolares, da organização institucional e do lugar social da educação escolar sejam consideradas.

Historicamente, a tarefa de se desenvolver e dinamizar novos mandatos institucionais no campo da educação deixou de lado uma das vozes que compõem a polifonia educacional, a dos alunos (cf. PEREIRA, 2010). Apesar de nos anos de 1970, na Inglaterra, surgir um movimento de investigação sobre aquilo que o corpo discente tinha a dizer, foi somente nos idos dos anos de 1990 que a epistemologia da escuta discente ganhou propulsão (TEIXEIRA; FLORES, 2010). Já agora se apresenta forte convicção nessa perspectiva designada como "voz do aluno", em que se avalia a importância de se conhecer o fenômeno da experiência escolar a partir das percepções e perspectivas dos atores que o vivem em primeira pessoa, os próprios alunos (CLARK; MOSS, 2001; TANGEN, 2008).

Além de se configurar como uma opção simultaneamente epistemológica e ética, essa corrente de estudos consagra também uma dimensão democrática da escola, uma vez que se observam considerações e opiniões dos alunos nas decisões tomadas no ambiente escolar,

\footnotetext{
${ }^{5}$ Em Portugal, a gestão das escolas realiza-se agrupando escolas de diferentes níveis de ensino com alguma proximidade geográfica que passam a constituir uma única entidade educativa.
} 


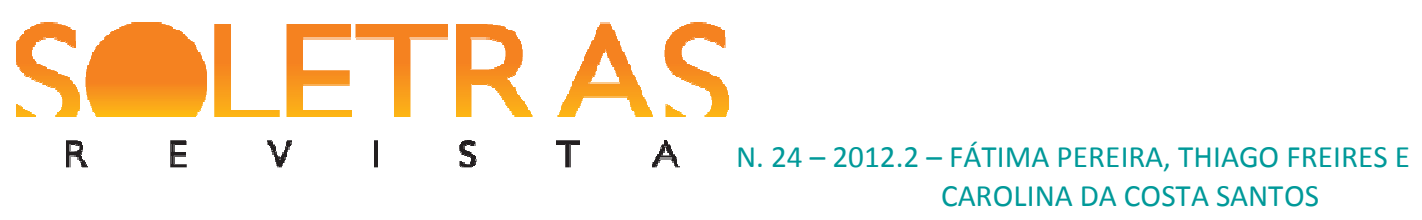

atribuindo a estes, nessa instância, um protagonismo na gestão educativa (FLUTTER; RUDDUCK, 2004). O trabalho de se fazer perceber na dinâmica escolar, aliás, importa especialmente porque significa ter consciência da capacidade de contribuir para a melhoria do sistema educativo (RUDDUCK; FLUTTER, 2004).

\section{Efeitos da escolaridade no percurso de vida dos alunos}

Permeado pelo referencial teórico apresentado até aqui, e consciente de que a audição da voz dos alunos significa, ainda, reconhecer que a escola está a falhar em seu projeto educativo, o OBVIE adota o princípio da subjetivação da experiência escolar, a fim de recolher dados que possam ser reveladores do nosso atual cenário educacional, na perspectiva de seu maior beneficiado (ou não) - o aluno. O projeto anterior deste Observatório da Vida nas Escolas, situado no contexto do (in) sucesso escolar, objetivou permitir que a voz dos alunos constituísse narrativas biográficas que dessem pistas sobre os obstáculos e os dispositivos de promoção de sucesso na vida escolar.

No projeto ao qual este artigo é vinculado, que corresponde ao trabalho realizado para o ano letivo europeu de 2011 / 2012, a experiência da significação de seu próprio percurso dá ao aluno uma oportunidade de refletir sobre sua postura e também sobre suas concepções de escola, o que no âmbito da investigação deverá ser revertido na construção sistemática das relações com o aprendizado.

Respeitando todo o quadro que se constrói com a investigação, a metodologia utilizada não podia diferenciar da qualitativa, que busca respeitar a subjetividade de cada sujeito da pesquisa. Recorremos às ideias de Pendlebury e Eslin (2002), de que "é importante distinguir a investigação conduzida sobre seres humanos da que é realizada com seres humanos: o 'sobre' faz desses seres objetos de investigação, enquanto o 'com' implica uma relação participativa e, pelo menos, algum grau de reciprocidade" (apud LIMA, 2006, p. 134). Assim, partimos de uma ideia de alteridade que enxerga os sujeitos da investigação como um outro participante da pesquisa.

Os sujeitos com que se fizeram entrevistas semiestruturadas do tipo biográfico são alunos/as que estão matriculados/as e frequentam a escola há pelo menos cinco anos. Os critérios de escolha dos/as alunos/as foram elaborados/decididos pela escola e partilhados com a FPCEUP (Faculdade de Psicologia e de Ciências da Educação da Universidade do Porto), 


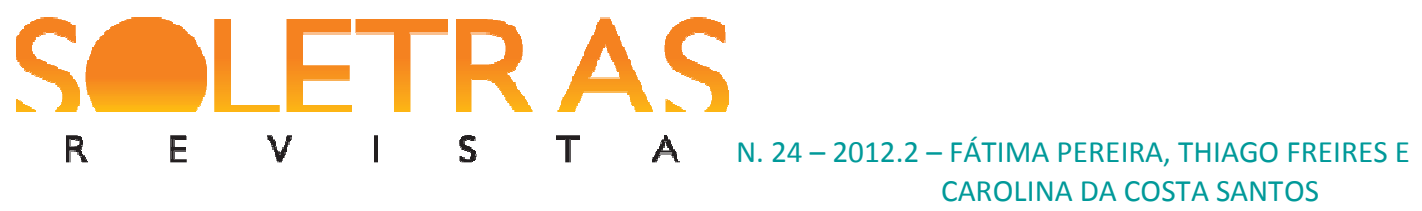

respeitando-se uma certa diversidade de identidades, como, por exemplo, alunos/as com sucesso ou insucesso marcados em seu percurso.

Quanto ao método da realização das entrevistas, tarefa executada por cada escola participante, foi orientado que não fosse um/a professor/a a efetivá-lo, a fim de não inibir respostas mais espontâneas dos alunos em razão da relação estabelecida entre docente e discente que envolve, também, avaliação, eliminando a ideia de se criar uma relação de tensão.

Dentre os objetivos da pesquisa, convém esboçar-se uma resposta sobre a evolução acadêmica, verificando, por exemplo, quantos anos levam os alunos de cada escola para cumprirem os seus respectivos cursos e quais são os principais obstáculos ao sucesso experienciados pelos estudantes. Sendo um dos pressupostos da pesquisa a apropriação dos resultados pelas escolas e um visível respeito ao seu funcionamento e à sua liberdade, a política que sustenta o vínculo das escolas ao projeto aqui referido assume que não é ético e proveitoso haver interesse de um lado só, revelando a participação das escolas movida pelo próprio interesse educativo da instituição. Desta forma, a participação existe porque as escolas querem e enquanto elas quiserem. O objetivo da pesquisa é construir relações de saberes com a escola e não para a escola ou em vez da escola, em uma substituição de preposições que altera de fato o protagonismo dos sujeitos em pesquisa.

Aceitando a participação na pesquisa, as escolas assumem o papel de realizar as entrevistas, baseadas em um guião flexível e útil para pensar o que é pertinente nesta conversa, mas não para determinar uma ordem rígida ou exclusiva para a recolha de dados. $\mathrm{O}$ guião foi elaborado pensando na caracterização não só dos/as alunos/as, mas na relação desses/as mesmos/as alunos/as com a escola. Estando lá há cinco anos, parte-se do princípio de que, o que os/as alunos/as são, em termos de identidade, tem relações com o que a escola fez ou não. Admite-se, assim, que o objeto de pesquisa permeia o impacto da escolaridade na construção da identidade dos alunos, e visa a entender até que ponto as opiniões dos alunos são modeladas pela escola onde eles se formam, se o são.

Defende-se, à partida, "que a escola não se confina à mera transmissão e ensino de saberes definidos, mas dedica-se à total formação dos alunos enquanto seres humanos, visto que o Homem é um ser complexo que contém em si o cultural, o social, o afetivo, o cognitivo e o físico" (PEREIRA, 2011, p. 2). Pretende-se compreender, através da escuta da voz dos alunos, como a escola contribui para a construção destas outras dimensões na vida de cada 


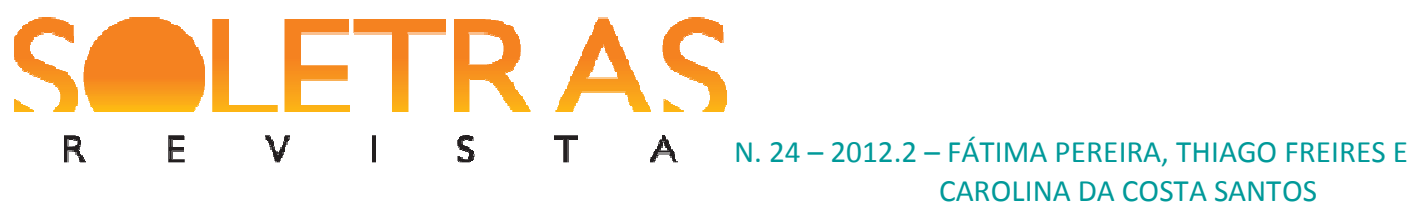

um, procurando identificar também os sentidos e significados que os alunos atribuem à escola e à sua vivência dentro desse espaço, visando a esboçar como estas vivências contribuem para formar o modo como estes sujeitos, por exemplo, se relacionam com o mundo, as expectativas que mantêm em relação ao futuro e as subjetividades que constroem e carregam ao longo da vida.

Entendendo que a educação autêntica "não se faz de A para B ou de A sobre B, mas de A com B, mediatizados pelo mundo. Mundo que impressiona e desafia a uns e a outros, originando visões ou pontos de vista sobre ele. Visões impregnadas de anseios, de dúvidas, de esperanças ou desesperanças que implicitam temas significativos" (FREIRE, 2008, p. 97), interessa-nos perceber como a escola influencia essas visões de mundo construídas por seus alunos.

Para este estudo, então, as dimensões contempladas no guião da entrevista dividem-se em dados de caracterização, perspectiva panorâmica sobre o percurso de vida do aluno entendendo-se que há vida além da escola -, envolvendo a educação familiar, o desenvolvimento pessoal e acadêmico, as relações com os colegas, com os professores e com o saber, a ação da escola sobre si e as perspectivas de futuro que envolvem, necessariamente, a educação.

\section{Participantes e procedimentos}

O OBVIE tem parceria ativa com dezesseis agrupamentos do Norte de Portugal, como já fora mencionado, mas somente oito deles participaram na realização do projeto acerca dos efeitos da escolaridade no percurso de vida dos alunos. No total, recolheram-se trinta e quatro entrevistas semiestruturadas, do tipo biográfico. Todos os entrevistados são estudantes do nono ano, o que corresponde ao último do terceiro ciclo, antecedendo, portanto, a entrada no secundário, de acordo com o sistema educativo português.

A dimensão dos efeitos da escolaridade nos percursos de vida dos/das estudantes é o desdobramento de um dos eixos de toda a pesquisa em voga. Por isso, o processo que compõe a seleção da amostra, aqui discutida, levou em consideração questões que também focavam interesses do trabalho realizado acerca das aprendizagens e climas de escola, além da investigação que contextualiza os saberes num processo de melhoria dos resultados dos alunos. 


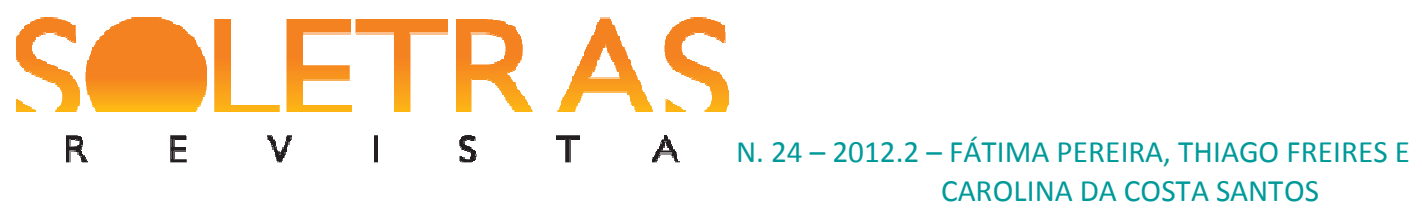

Cada escola participante foi instruída, portanto, a selecionar dez alunos, de cinco turmas diferentes do nono ano, que estivessem frequentando aquele estabelecimento há pelo menos cinco anos. Os nomes deveriam ser iniciados com as últimas letras do alfabeto, no intuito de evitar enviesamentos com o gênero. Deste grupo de sujeitos, representantes das próprias escolas deveriam eleger cinco estudantes que pudessem participar de uma recolha aprofundada de dados, mediante aplicação de entrevistas. A reflexão para esta seleção final deveria atender uma diversidade dos critérios de gênero, origem social e acadêmica, além de considerar o percurso escolar existente na instituição de ensino.

Dessa forma, as entrevistas foram colhidas e transcritas pelos próprios profissionais das escolas, sendo posteriormente submetidas à equipe de investigação da FPCEUP. No momento em que foram reunidas as entrevistas das diversas instituições participantes, todas as informações relativas à identidade física dos sujeitos da investigação foram suprimidas. Esses dados são de caráter confidencial e os nomes que se mencionam em trechos aqui divulgados são fictícios.

Entendemos a singularidade e o protagonismo de cada sujeito, mas quanto aos estudos com narrativas, compreendemos que "o que há a compreender na narrativa não é tanto o seu autor mas aquilo sobre o que se falou, o mundo humano da ação que é refeito pelo texto (PEREIRA, 2011, p.64)". Assim como Correia (1998), assumimos que as narrativas não deixam a investigação menos lúcida por se apoiar nos textos dos personagens principais da escola, a saber, os alunos; trata-se apenas, como realça também Latour, de reconhecermos aos sujeitos-objetos educativos o "direito e a dignidade de serem narrativa" (LATOUR, 1991, p. 123) e de considerarmos as estruturas do mundo vivido como "regras gerais de interpretação, segundo as quais o actor define a situação da vida quotidiana e se define a si próprio" (Habermas, apud CORREIA, 1998, p. 184).

A equipe que se debruça na investigação é composta por uma professora titular, uma investigadora e dois bolsistas de investigação, que são alunos do mestrado em Ciências da Educação. A discussão que se segue abaixo traz um panorama da primeira leitura do material, o que vem a compor um mapeamento de questões pertinentes para uma análise mais aprofundada, levando-se em consideração a origem de uma nova etapa investigativa. 


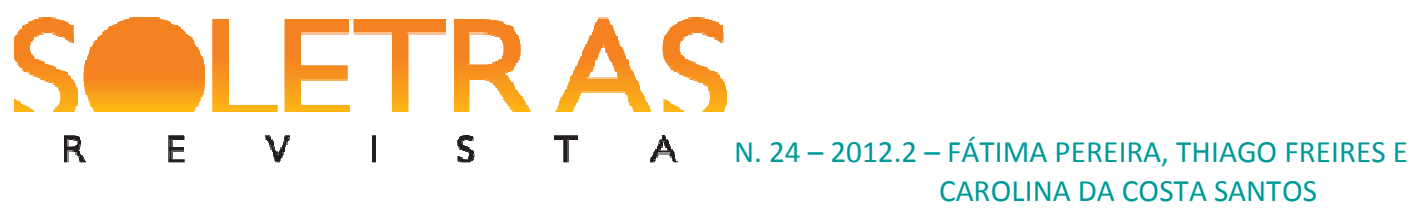

O trabalho realizado no âmbito do OBVIE agora se associa ao projeto IJUP ${ }^{6}$, em que há um esforço no sentido de conjugar áreas diversas do saber, isto é, o objeto de estudo é submetido a uma visão transdisciplinar. Assim, o resultado final da investigação que se debruça sobre as entrevistas recolhidas será o produto de um estudo realizado em parceria com o Departamento de Sociologia da Faculdade de Letras, também da Universidade do Porto. A equipe de investigação passa a contar então com uma professora titular e uma bolseira de investigação do referido departamento.

Cabe ainda ressaltar que, para essa etapa subsequente, seis estudantes dos trinta e quatro que participaram da primeira recolha de dados serão convidados a realizar novos encontros, agora com os próprios investigadores do projeto, a fim de se compor narrativas biográficas. Pretende-se, com esse procedimento, aprofundar e dar maior consistência às questões identificadas como relevantes no estudo dos efeitos da escolaridade na vida desses/as alunos /as.

\section{Entre linhas: discussão e considerações sobre entrevistas}

As entrevistas, ao abordarem dimensões amplas, flexíveis e abertas, permitiram cada estudante destacar aspectos que mais interessavam a ele próprio. Respeitamos, metodologicamente, esta flexibilidade e a abertura do guião porque compartilhamos a ideia de Leibowitz et al.: "We were aware that they [estudantes], like all individuals in interview situations, make strategic and rhetorical choices about how they portray themselves (Sousin, 2009; Edwards, 1997) ${ }^{7}$. Because they are constructing their identity and sense of self as they tell their stories" (LEIBOWITZ, 2012, p. 358).

Como técnica da metodologia do projeto, alguns alunos participarão de novas conversas a fim de estabelecermos narrativas biográficas que permitam aprofundar os percursos escolares e seus efeitos nas histórias de vida destes sujeitos. Acreditamos que as narrativas são uma forma de exposição de si, de reflexão e de partilha e que podem ser vistas também como uma proposta de busca pela subjetividade perdida, que dá outros contornos aos sujeitos e aos temas pesquisados.

\footnotetext{
${ }^{6}$ A Investigação Jovem na Universidade do Porto (IJUP) é um programa de caráter pluridisciplinar que estimula a participação de estudantes da licenciatura e do mestrado na realização de investigação científica.

${ }^{7}$ Autores citados por Leibowitz (2012).
} 


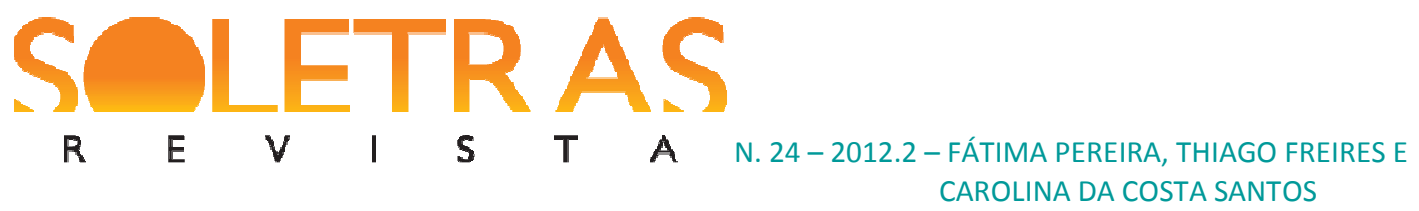

Discutimos agora os resultados de uma análise de conteúdo inicial feita com trinta e quatro entrevistas com alunos das diferentes escolas, já mencionadas anteriormente. São reflexões que se destacaram nas primeiras leituras das entrevistas transcritas. Assim, são assuntos que emergiram das leituras, nos fazendo compreender, a saber, uma relação forte entre a vida familiar e a vida escolar dos alunos no que tange a pontos positivos e negativos, e identificar as significações que os alunos atribuem à figura do bom e do mau professor.

No que tange as relações entre a vida familiar e escolar, percebe-se que nas entrevistas há momentos em que os assuntos são pontos, aspectos ou alguns episódios positivos e negativos que tenham acontecido na vida familiar do/a aluno/a e também no âmbito escolar. Lendo suas respostas, constatamos que podemos aproximar os níveis pessoal e escolar pela coincidência das respostas. O que é tido como positivo na família também o é na escola, o que ocorre na mesma intensidade para os episódios negativos, havendo uma correspondência entre algumas expectativas que os/as alunos/as sempre têm, tanto em casa quanto no ambiente escolar.

$\mathrm{O}$ que os/as alunos/as mencionam, em grande maioria, como aspectos positivos e negativos está vinculado a dois temas maiores, que agrupamos em união e separação. Os melhores pontos da família giram em torno da cumplicidade e da amizade entre os membros da família, sendo os episódios mais memoráveis as férias em que todos estão juntos ou mesmo momentos em casa onde todos estão, como a ver a TV à noite. Entre pontos positivos em casa citamos algumas falas: "nas férias, na praia, quando estou com eles [meus pais] sintome feliz" (Rodrigo) ${ }^{8}$, "Meus pais fazem tudo por mim" (Maria); "Estamos na maior parte do tempo juntos na sala, à noite" (José); "Tive a sorte de ter os avós sempre em casa (...) e também tive a sorte de encontrar pessoas felizes e boas" (André).

Quando o entrevistador pede para o/a aluno/a imaginar a possibilidade de mudar algo na vida familiar, os adolescentes, sem hesitar, afirmam que buscariam mais momentos com a família ("ficaria mais próxima do meu pai” (Gabriela)), mais união e menos conflitos entre seus membros. Há alunos/as que gostariam de refazer o casamento dos pais: "Se eu pudesse eu unia os meus pais, não é?” (Flávia); outros diminuiriam a distância da casa dos parentes: “Gostava que morassem mais próximo uns dos outros, os meus familiares" (Rodrigo); ou evitariam conflitos entre os membros da família, buscando "mais amizades de todos. Em todas as famílias há sempre conflito" (Carla); ou ainda, realizariam almoços e reuniões para

\footnotetext{
${ }^{8}$ Todos os nomes mencionados ao longo do artigo são fictícios. 


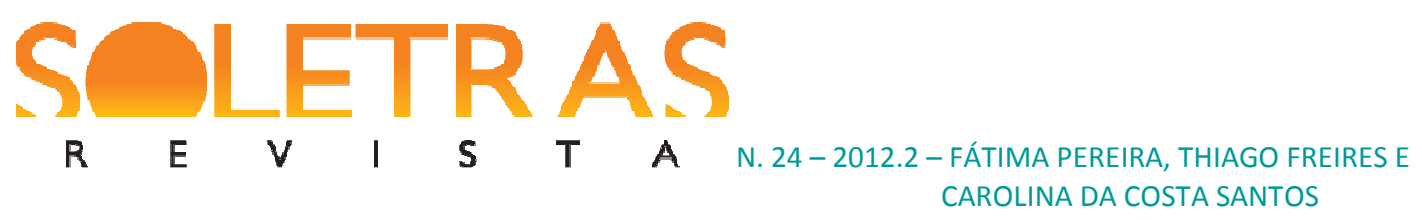

prolongar eventos de união e "estar mais calma com eles, ter mais tempo para falar com eles" (Bianca).

Em oposição, mas complementando o nosso estudo, nos pontos negativos e episódios dos quais não gostaram, encontramos a separação como eixo que engloba os aspetos pontuados pelos/as alunos/as: a morte e a tristeza dos funerais estão como primeira citação de momentos desagradáveis, seguida pelos conflitos constantes ou esporádicos entre a família, a separação dos pais e até mesmo uma mencionada traição. Algumas vozes que podem clarificar isto são trazidas ao artigo como respostas à pergunta sobre aspectos negativos da vida familiar ou como menções feitas em outras partes das entrevistas que nos levam ao mesmo assunto: "eu gosto da minha irmã e ela não gosta de mim (...). Ela não gosta de mim. Eu noto!” (Fernando); “[um episódio menos bom é] quando discute comigo também por causa das notas. Andamos os dois à porrada" (Gabriela); "os meus irmãos mais velhos se pegaram, discutiram e tivemos que os separar" (Flávia).

É interessante observar que estes mesmos aspectos da vida familiar entram com os jovens na escola. Também entre união e separação estão relacionados os pontos positivos e negativos. Os amigos feitos e mantidos são o principal motivo de satisfação com a escola, de acordo com os/as alunos/as. As amizades são um ponto positivo, junto com a proximidade dos/as professores/as, a boa relação de uma turma inteira, portanto. Os episódios marcantes envolvem, por exemplo, a turma específica de determinado ano por ter sido muito unida, sem problemas de relacionamento. Reproduzimos, a título de amostra, algumas falas que traduzem estes pontos positivos, evitando, claro, a repetição daquelas que remontam à amizade para que a leitura não ficasse exaustiva: “[Eu gosto do] envolvimento com professores e funcionários, amigos" (Antónia); "Gosto quando tenho boas notas, de me esforçar e amigos" (Ricardo); "Estar com os amigos" (Juliana - fala que resume muitas outras).

$\mathrm{Na}$ escola, determinados/as alunos/as surgem como motivo específico, ou melhor, são citados como os próprios aspectos negativos. São mencionados/as como perturbadores/as de certa ordem escolar, como desestabilizadores/as da união da turma ou da escola, podendo, eminentemente, romper a união. Assim, buscando os pontos negativos citados pelos/as estudantes, observamos que eles também estão no campo da separação, do conflito negativo, isto é, as incompatibilidades não propiciam uma negociação ou a revisão conjunta de valores, mas desembocam no isolamento como última instância, seja pela agressão física ou pelo distanciamento moral. Além de alunos/as específicos/as e seus comportamentos, o que vem à 


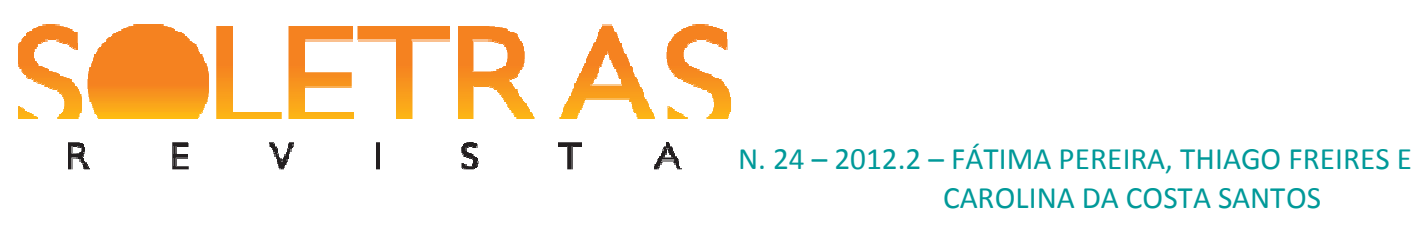

tona quando eles/as discorrem sobre aspectos desfavoráveis na escola, apresentam-se novamente desentendimentos, sendo estes discussões e até mesmo brigas físicas. A violência, desta forma, está relacionada à separação que pode vir a corromper o ideal de harmonia e união pelo qual os/as alunos/as tanto prezam.

"[Gosto menos] da violência, dos mais velhos a maltratar os mais fracos" (Ana); "Pessoas que fazem picarulias" (Beatriz); "alunos que não deviam estar lá" (Carla); "eu e um colega meu andamos à porrada, mas agora somos amigos" (Jorge); "Quando estava com colegas nos intervalos alguém nos chateava sem razão... era outro aluno, eu ignorava, colegas meus já não (...) Isso acontecia, chateava com insultos e pontapés" (Ricardo); "Quando amigos andam às turras uns com os outros" (Bruno) são algumas falas com imagens que podem exemplificar os aspectos negativos mencionados pelos alunos entrevistados.

No âmbito escolar também se revela importante o fato de aparecerem o reconhecimento do sucesso e do insucesso escolar como marcos positivos e negativos, respectivamente. Alguns/mas alunos/as referem-se a prêmios que receberam por desempenho e mérito individual como episódio marcante. Outros/as alegam como dia marcante a vitória em algum campeonato ou uma boa classificação em algum concurso que ocorrera na escola. Nessa mesma esteira, como ponto negativo encontramos o fato de o/a estudante não ter conseguido atingir objetivos propostos, exames mal sucedidos, esforço não recompensado e até mesmo a falta de esforço. Ainda algumas falas dos alunos podem desenhar estas observações. Como acontecimentos positivos aparecem: "No sétimo ano eu tirei $5^{9}$ em tudo" (Fernando); "Quando saí por receber um prémio por excelência e mérito"; "Quando eu participei das Olimpíadas e fiquei em $1^{\circ}$ lugar"; "Quando ficamos em $1^{\circ}$ lugar no interturmas"; "O que mais me marcou foi ano passado quando fomos campeões do desporto escolar"; "Ser o melhor aluno do ano passado", enquanto os aspectos negativos se resumem a "não gosto, se calhar, tem a ver quando me chateio com alguém, ou quando não consigo atingir um objetivo que pretendo" (André).

Outro eixo bastante explícito nas entrevistas e alocado de forma direta é o do relacionamento entre alunos/as e professores/as. Se num primeiro instante indaga-se sobre a representação que os pais fazem destes profissionais, no decorrer das narrativas é o/a próprio/a aluno/a que assume a responsabilidade da fala e caracteriza o que são bons e maus educadores.

\footnotetext{
${ }^{9}$ Até o fim do terceiro ciclo (nono ano) em Portugal, as notas atribuídas vão de 0 a 5. 


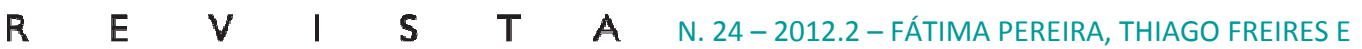 CAROLINA DA COSTA SANTOS}

O discurso direto empregado pelos/as alunos/as dá margem à construção de uma caracterização cujo exame permite perceber de que forma a experiência escolar leva alunos/as a designar o que lhes parece ético e respeitável na conduta de professores/as, ou não. A partir da voz destes estudantes, podemos compor a figura do professor por meio do reconhecimento de três grandes categorias: relações interpessoais, formação profissional e gestão dos processos de aprendizagem.

No campo das relações, há questões que se relacionam com os temas da ética, da humanização e do profissionalismo. O discurso dos alunos revela, por exemplo, uma repulsa a professores/as que claramente privilegiam alguns estudantes nas práticas escolares: "[Não gosto dos professores] quando ensinam mal. E quando gostam mais de um aluno e deixam o resto à porta" (Maurício). Evidencia-se interesse por um profissional que não somente seja capaz de cumprir seu papel didático, mas também supra uma necessidade que é mesmo do campo afetivo: "Penso que [os maus professores] são aqueles com quem não há uma ligação, não estabelecem uma ligação com os alunos, estão sempre com uma maneira muito fria. Se calhar, ao falar, vou encontrar imensos professores, assim, que vão ser bons professores, mas neste momento, penso que não estabelecer uma ligação com os alunos de uma forma afetiva, não ter disponibilidade para estar lá sempre, para nos ajudar quando for preciso [caracteriza o mau professor]" (Augusto).

A questão das relações, de certa forma, transcende para outros domínios e se faz notar também quando o corpo discente discute a forma como os/as professores/as transparecem seu apreço por sua formação profissional em sala de aula “[...] há professores que são professores, mas não têm carisma. Acho que é preciso gostar, mesmo gostar do que se faz porque envolve imenso trabalho e [...]" (Mateus). Numa outra recolha, um estudante destaca que "tem que ser, acho que motivado porque alguns professores parecem mesmo fazer uma obrigação" (Vinicius), trazendo à discussão a importância do compromisso com o trabalho e os efeitos da manutenção deste.

Outra área que se configura rica no apontamento de dados, tanto no sentido de definir o que vem a ser um bom ou mau docente, é a da gestão dos processos de aprendizagem. Provavelmente, porque é a experiência dessa dimensão, aquela que tem efeito mais imediato no corpo discente. $\mathrm{O}$ interesse por uma escola que seja inovadora, motivadora e diferente vem alimentada na representação dos/as professores. São eles/as, os/as responsáveis por tornar a sala de aula um espaço monótono: “[Não gosto] Quando eles dão, não (...) quando é para 


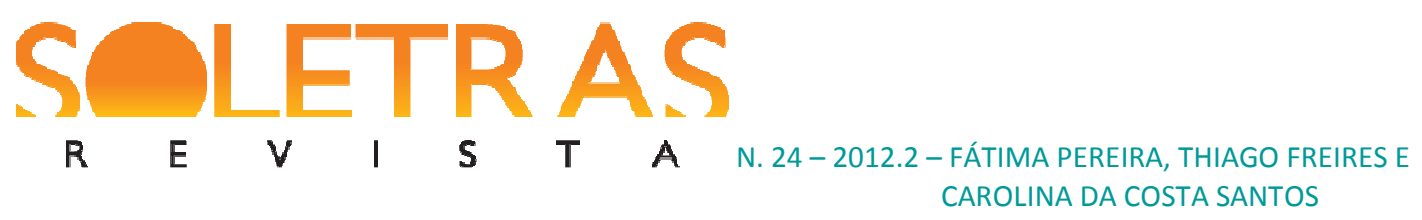

transcrever grandes textos nos quadros e nós temos que estar a passar isso." (Bianca) ou dinâmico, comprometido com os atores envolvidos no processo "[Gosto] Quando o professor tem as aulas animadas e também percebe-nos a nós quando a gente quer falar, percebe o nosso lado" (Thainara).

Como se nota, a partir das falas dos/as estudantes entrevistados/as, de modo geral, as características que asseguram positivamente o lugar do/a professor/a no âmbito escolar remetem à compreensão, à preocupação com as necessidades de aprendizagem e o respeito à figura do/a aluno/a, enquanto do lado negativo a rejeição parece se associar com o caráter autoritário e centralizador do/a professor/a, especialmente ilustrado no descontentamento dos/as jovens pelos berros proferidos em sala e a eventual desmotivação do docente.

Claramente, podemos associar os relatos desses/as estudantes a outros trabalhos que abordam a subjetivação das relações entre professores/as e alunos/as no espaço escolar. Num estudo semelhante realizado por Day (2001), o autor utiliza relatos de estudantes para definir o que seria o mestre adequado. O profissional relatado em sua obra se sustenta como aquele que gosta de ensinar, torna as aulas interessantes, é justo e acessível, características que também se sobressaem na voz dos alunos entrevistados pelo OBVIE. Importa perceber, todavia, que o sentido que se pode atribuir aos valores destacados pelos/as estudantes nem sempre é universal. Acessibilidade, dinamismo e interação podem tomar diferentes formas, de acordo com o contexto histórico, social e temporal de que estamos a avaliar.

\section{Conclusões preliminares}

Quando descreve a experiência da visita a uma escola dos dias de hoje, Lopes (1996) afirma que "deparamos com muitas reminiscências das escolas de ontem: a cultura reificada; a organização burocrática, a dependência das instâncias centrais, os espaços uniformizados e desagradáveis, a distância entre professores e alunos, a prevalência da aula como espaçotempo aglutinador, o desencanto e desmotivação dominantes" (apud ABRANTES, 2003, p. 107). As ideias do texto escrito nos idos anos noventa do século XX parecem-nos ainda muito atuais no que se refere ao clima escolar do novo século, o XXI, passada já uma década inteira.

$\mathrm{Na}$ perspectiva de se observar a escola enquanto instituição multifacetada, Abrantes (2003) salienta que é importante reconhecer, também, que há em alguns nichos, o desenvolvimento de uma nova face da identidade escolar. Uma face que permite construir 


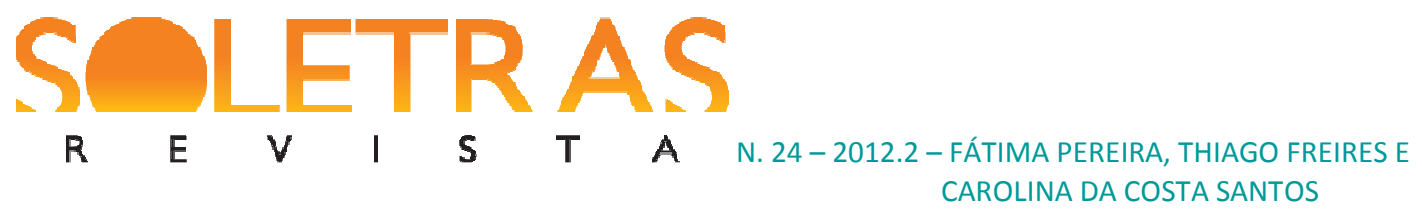

novas relações entre os protagonistas da educação e que se alicerça, especialmente, na cultura de características como a informalidade, a criatividade, a iniciativa e o entusiasmo. De certo modo, podemos enquadrar os relatos dos jovens consultados pelo OBVIE no espectro da tensão entre a tradição velha e engessada e o espaço da iniciativa que, alheia a modelos rígidos, ajuda a desconstruir conceitos educativos sob o entusiasmo de oferecer novos significados a eles. Não se trata, todavia, de perceber todo o desejo de mudança e transformação sob a ótica de uma ruptura exaustiva. É, na verdade, um exercício de redimensão das relações no preceito do acordo, entre as vozes, que compõe o ambiente escolar. Espera-se, não a mera supressão dos conflitos, mas a transformação destes em aprendizagens significativas.

Nesse sentido, tanto os conflitos no âmbito familiar quanto as reclamações no seio da escola (o que inclui as características indesejadas na figura do professor), destacadas pelos/as alunos/as na recolha de entrevistas, nos permitem reconhecer a necessidade de que o diálogo se sobreponha a qualquer atitude. A redimensão da escola no intuito de investir-se em motivação, proporcionando respeito a uma diversidade de percursos, é um trabalho conjunto. Quanto à rejeição do professor "que berra", por exemplo, Paulo Freire já alertava que "não há diálogo se não há humildade. A pronúncia do mundo, com que os homens o recriam permanentemente, não pode ser um ato arrogante" (FREIRE, 2008, p. 92).

Torna-se importante salientar algumas considerações que são possíveis através desta análise inicial dos resultados: permeando todas as narrativas desse estudo, presente nas trinta e quatro entrevistas, de forma direta ou pelas entrelinhas, é fundamental perceber como (em termos de intensidade, falamos) está marcada a necessidade do trabalho humanizado. Como reflexão deste breve contato com as entrevistas, podemos observar que o conteúdo deste material, lido de forma atenta aos assuntos que são tocados e aqueles que emergem do discurso dos/as alunos/as, nos prende antes de tudo à ideia de que as escolas são construídas primeiramente por pessoas e para elas.

A união e a separação nas quais podemos encaixar a fala dos/as alunos/as nos remetem às relações humanas, à interação constante e fundamental na nossa vida. As relações próximas e cúmplices como aspecto positivo em detrimento de conflitos e da separação mencionadas pelos/as alunos/as como pontos negativos alertam para a questão humana da escola, para a necessidade de se levar em conta que antes de espaços físicos, currículos ou projetos, a escola é constituída de pessoas que se relacionam, se envolvem e se influenciam. 


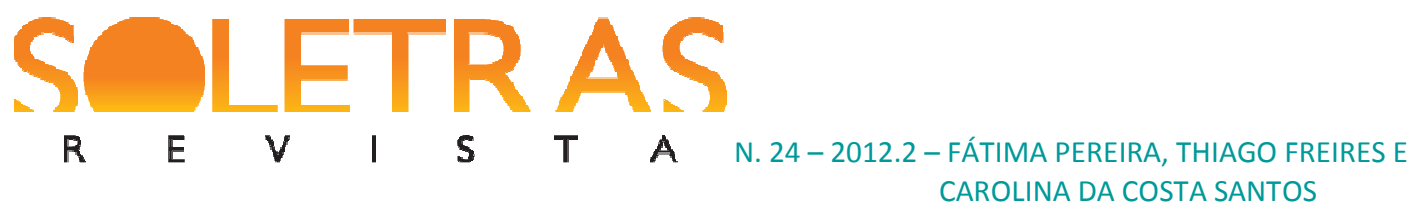

Como pontos positivos aparecem, portanto, as amizades, a relação saudável com/entre os funcionários, o todo harmonioso da turma e da escola - tanto nos aspectos micro, quanto nos macro. Entre aspectos negativos observam-se os desentendimentos, as brigas, o desequilíbrio de um ambiente amigável, tanto em casa quanto na escola. E neste último ambiente recai a exigência de se pensar cada vez mais e, antes de tudo, na escola como constituída por pessoas, não isoladamente, mas na relação entre elas. Guiados, assim, pelas entrelinhas que o discurso dos/as estudantes revelam, percorremos agora uma trilha mais bem definida, a fim de aprofundar não somente que sentidos dão os estudantes à escola, mas que efeitos esta instituição, de fato, condensa em suas vidas. O diálogo está aberto.

\section{Referências bibliográficas:}

ABRANTES, Pedro. Os sentidos da escola: identidades juvenis e dinâmicas de escolaridade. Oeiras: Celta, 2003.

CLARK, A.; MOSS, P. Listening to children: the mosaic approach. London: National Children's Bureau, 2001.

CORREIA, José Alberto. Para uma teoria crítica em educação. Porto: Porto Editora, 1998.

DAY, Christopher. Desenvolvimento profissional de professores: os desafios da aprendizagem permanente. Porto: Porto Editora, 2001.

FLUTTER, J.; RUDDUCK, J. Consulting pupils: what's in it for schools. Londres: Routledge Falmer, 2004.

FREIRE, Paulo. Pedagogia do oprimido. Rio de Janeiro: Paz e terra, 2005.

LEIBOWITZ et al. "It's been a wonderful life": accounts of the interplay between structure and agency by "good" university teacher. High Educ., 63. 2012, p. 353-365.

LIMA, Jorge Ávila de. Ética na investigação. In: LIMA, Jorge Ávila de; PACHECO, José Augusto (Orgs.). Fazer investigação: contributo para elaboração de dissertações e teses. Porto: Porto Editora, 2006.

MOURAZ, Ana; PEREIRA, Fátima. Cognitive work developed by students: From The Importance To The Promotion. International online Journal of Educational Sciences, 3 (3), 849-864, 2011.

PEREIRA, Fátima. Infância, educação escolar e profissionalidade docente: um mapeamento social dos discursos em formação inicial de professores. Lisboa: Fundação Calouste Gulbenkian; Fundação para a Ciência e a Tecnologia, 2010. 


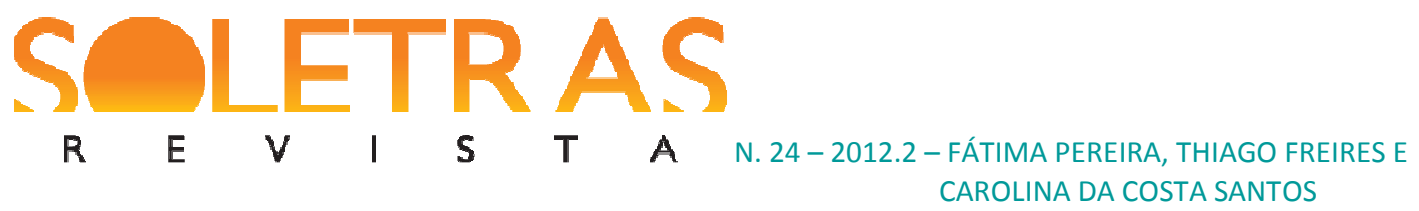

PEREIRA, Fátima. Referencial teórico para o projecto "Sentidos e significados da vida na escola: um estudo exploratório em vozes do/a aluno/a”. Porto: CIIE, 2011.

TANGEN, R. Listening to children's voices in educational research: some theoretical and methodological problems. European Journal of Special Needs Education 23, 2, 157-66, 2008.

TEIXEIRA, C.; FLORES, M.A. Experiências escolares de alunos do ensino secundário: resultados de um estudo em curso. Educação e Sociedades, Campinas, SP, 31, 110, 113-133, jan.-mar. 2010.

\title{
Effects of formal education in student's lives: between the narrative lines
}

\begin{abstract}
This article discusses the effects of schooling throughout the life of students from some of Portuguese schools that, along with the Centre for Research Education (CIIE) of the University of Porto, make up the Observatory of Life in Schools (Observatório da Vida nas Escolas - OBVIE). The research project aims at understanding the effects on the students' lives caused by the institution in which they experience their school life. This article focuses on the implicit discourse observed in biographical interviews. The interviews, whose topics were decided by the university and the schools involved in the project, were carried out with students of the ninth year from diverse schools and represent an investigation method that enables highlighting the students' voice. This research is based on a theoretical ground that privileges the epistemology of students hearing. The article relevance lies especially on highlighting the importance of students' voice in the polyphony present at schools in order to help realizing the meaning they attribute to the institution in its different perspectives. As initial results of an ongoing research, we highlight that the students" "scream" is based on a search for integration and a humanized work in all of school departments, drawing attention to the fact that besides having a physical structure, curriculum and methodologies, the school is made up of people.
\end{abstract}

Keywords: School. Students' voice. School Experience.

Recebido em: 15 de dezembro de 2012.

Aprovado em: 02 de janeiro de 2013. 